\title{
ANALISIS KOMPETENSI PROFESIONAL CALON GURU PAI IAIN BATUSANGKAR BERDASARKAN GENDER
}

\author{
Rizki Pebrina ${ }^{1}$ \\ ${ }^{1}$ IAIN Batusangkar, Sumatera Barat, Indonesia \\ rizkipebrina@iainbatusangkar.ac.id
}

\begin{abstract}
Abstrak
Having professional competence is a must for prospective teachers. Professional competence of Islamic Education prospective teacher can be seen from the ability to master the theories of Islamic Education. Based on the author's observations on their abilities in mastering and explaining the theories, female prospective teachers are better than male prospective teachers. This research was conducted through observation. The research result shows the professional competence of prospective teachers of Islamic Education in sufficient category. Based on gender, female students gain better competence (59,9\%) than male students $(55,2 \%)$.
\end{abstract}

Keywords: Professional Competence, Prospective Teachers, Islamic Education

\section{PENDAHULUAN}

Kompetensi profesional merupakan salah satu aspek yang mesti dimiliki oleh seorang guru dan calon guru. Kompetensi profesional yaitu kemampuan penguasaan materi pembelajaran secara luas dan mendalam yang memungkinkannya untuk membimbing peserta didik dalam memenuhi standar kompetensi yang ditetapkan dalam Standar Pendidikan Nasional (Triyanto, 2007:72). Kompetensi profesional ini sangat besar pengaruhnya terhadap motivasi dan hasil belajar. Hal ini didukung dengan penelitian Sulistyowati, dkk "Pengaruh Motivasi Belajar dan kompetensi profesional guru terhadap prestasi belajar mata pelajaran IPS" dimana terdapat pengaruh yang antara kompetensi profesional guru terhadap prestasi belajar siswa dengan nilai kontribusi parsial sebesar 28,40\% (Sulistyowati,2012:2).

Di samping itu, tantangan guru PAI masa depan adalah guru yang tidak hanya memenuhi persyaratan secara akademik akan tetapi diperlukan profil guru yang ideal dan profesional di bidangnya. Hal ini juga sejalan dengan hasil penelitian yang ditulis oleh M. Nasir tentang Profesionalisme Guru
Agama Islam (Sebuah Upaya Peningkatan Mutu Melalui LPTK yang menjelaskan bahwa tantangan guru Pendidikan Agama Islam (PAI) di masa depan sangat besar dan berat. Oleh sebab itu, diperlukan profil guru yang ideal dan profesional yang mampu melakukan tugas pengajaran dan pendidikan untuk menghadapi berbagai tantangan zaman di masa depan. Guru ideal dan profesional yang diharapkan adalah guru PAI yang memiliki empat kompetensi utama yaitu kompetensi paedagogik, personal, sosial dan profesional.( Nasir, 2013).

Pada dasarnya hasil penelitian yang telah dipaparkan di atas menguatkan bahwa kompetensi profesional merupakan suatu keharusan bagi guru dan calon guru.Sehingga dengan adanya kompetensi tersebut guru dituntut mampu menguasai ilmu yang akan diajarkan di sekolah/madrasah secara luas dan mendalam serta dapat menjalankan tugas keprofesionalannya dengan baik dan maksimal. Berdasarkan pengamatan, penulis melihat terdapat perbedaan penguasaan materi mahasiswa perempuan dan laki-laki. Hal ini terlihat pada saat mata kuliah microteaching, dimana mahasiswi dianggap 
lebih menguasai materi yang akan disampaikan, serta memiliki persiapan dibanding mahasiswa.

\section{METODE}

Jenis penelitian ini adalah penelitian lapangan (field research) dengan pendekatan deskriptif kuantitatif. Adapun yang menjadi populasi dari penelitian ini adalah semua mahasiswa PAI semester VI tahun akademik 2017/2018 yang berjumlah 106 orang. Teknik pengambilan sampel yang akan dilakukan pada penelitian ini adalah pengambilan secara acak. Artinya setiap pengambilan populasi atau unit dalam populasi mendapat kesempatan yang sama untuk dipilih sebagai sampel.
Teknik pengumpulan data yang digunakan adalah observasi. Dalam melakukan pengamatan peneliti menggunakan pedoman berupa lembar observasi. Item yang akan di amati dirumuskan berdasarkan indikator dari kompetensi profesional. Analisis data yang digunakan adalah analisis statistik deskriptif. Statistik deskriptif adalah statistik yang digunakan untuk menganalisis data dengan cara mendeskripsikan atau menggambarkan data yang telah terkumpul. Penyajian data bisa dilakukan melalui tabel, grafik, diagram, perhitungan persentase, desil, persentil. Analisis data dalam penelitian ini dilakukan dengan langkahlangkah sebagai berikut:

a. Menghitung jumlah skor untuk setiap butir pernyataan sesuai dengan aspek yang diamati

b. Menghitung skor Rata-rata (SR) dengan modifikasi rumus yaitu:

$$
\mathrm{SR}=\quad \frac{\text { Jumlah skor mahasiswa }}{\text { Jumlah skor ideal }} \times 100
$$

c. Menghitung persentase penilaian untuk masing-masing item indikator dengan cara:

$$
\mathrm{PP}=\quad \frac{\text { Jumlah skor mahasiswa per indikator }}{\text { Jumlah skor ideal }} \times 100
$$

d. Menafsirkan persentase masing-masing item indikator dengan modifikasi rumus yaitu sebagai berikut:

\begin{tabular}{|c|c|l|}
\hline NO & INTERVAL \% & \multicolumn{1}{c|}{ KATEGORI } \\
\hline 1 & $81-100$ & Sangat Mampu \\
\hline 2 & $61-80$ & Mampu \\
\hline 3 & $41-60$ & Cukup Mampu \\
\hline 4 & $21-40$ & Kurang Mampu \\
\hline 5 & $0-20$ & Tidak Mampu \\
\hline
\end{tabular}

\section{HASIL PENELITIAN DAN PEMBAHASAN}

Hasil penelitian ini diperoleh dengan cara menyusun sejumlah item pernyataan yang mengacu kepada indikator yang ada tentang kompetensi profesional, kemudian peneliti melihat performance mahasiswa yang menjadi sampel penelitian, dalam hal ini peneliti bertindak sebagai observer. Kisikisi yang akan disusun selain merujuk pada teori penulis juga mengembangkan dari penilaian kinerja guru (PKG) yang merupakan tindak lanjut dari Permenegpan dan RB No.16/2009 tentang jabatan fungsional guru dan angka kreditnya yang mana secara keseluruhan peraturan ini mengandung semangat yang bertujuan untuk meningkatkan kompetensi dan profesionalisme guru sebagai tenaga profesional yang mempunyai fungsi untuk meningkatkan mutu pendidikan nasional. Dari beberapa rumusan indikator yang ada, maka penulis membuat kisi-kisi berdasarkan indikator yang bisa penulis amati sesuai 
dengan objek yang akan diteliti maka instrumen yang digunakan berjumlah 17 item.

Setelah dilakukan penelitian maka didapatkan gambaran bahwa Jika diklasifikasikan berdasarkan jenis kelamin terkait kompetensi profesional calon guru PAI laki-laki dan perempuan maka didapatkan gambaran bahwa persentase kompetensi profesional mahasiswa perempuan diperoleh sebesar 59,9\% dengan kategori "cukup mampu". Sedangkan persentase untuk mahasiswa laki-laki didapatkan sebesar 55,2 \% dengan kategori "cukup mampu". Meskipun dalam kategori yang sama akan tetapi persentase yang diperoleh oleh mahasiswa berjenis kelamin perempuan lebih tinggi dibandingkan mahasiswa berjenis kelamin laki-laki selisihnya sebesar $4,71 \%$.
Dari 17 item yang diamati, penulis melihat ada beberapa item yang secara keseluruhan baik laki-laki maupun perempuan memiliki persentase yang masuk dalam kategori cukup. Artinya ada beberapa hal yang mesti dilakukan oleh mahasiswa calon guru namun hal tersebut masih sulit untuk dilaksanakan seperti item 6 terkait kemampuan mahasiswa dalam menyajikan materi secara kreatif. Baik laki-laki maupun perempuan perlu ditingkatkan lagi. Di samping itu pada item 12,13 , dan 14 terkait kemampuan mahasiswa dalam memberikan informasi yang mutakhir,memberikan contoh yang berbeda yang relevan dengan materi serta kemampuan mengintegrasikan materi juga perlu ditingkatkan lagi. Agar lebih jelas gambaran hasil observasi yang diperoleh dapat dilihat di dalam tabel di bawah ini:

Tabel 1.1

\begin{tabular}{|c|c|c|c|c|c|c|c|c|c|c|c|c|c|c|c|c|c|c|c|c|}
\hline \multicolumn{21}{|c|}{ REKAPITULASI HASIL OBSERV ASI PENELITIN } \\
\hline \multicolumn{21}{|c|}{ BERDASARKAN JENIS KELAMIN } \\
\hline \multirow[b]{2}{*}{ No } & \multirow[b]{2}{*}{ NAMA } & \multirow[b]{2}{*}{ JK } & \multicolumn{17}{|c|}{ SKOR BÜIIR } & \multirow[b]{2}{*}{ JMF } \\
\hline & & & 1 & 2 & 3 & 4 & 5 & 6 & 7 & 8 & 9 & 10 & 11 & 12 & 13 & 14 & 15 & 16 & 17 & \\
\hline 1 & R.AP & $\mathrm{p}$ & 3 & 3 & 4 & 3 & 3 & $\vdots$ & 3 & 4 & 3 & 4 & 4 & 2 & 2 & 2 & 4 & 3 & 3 & 53 \\
\hline 2 & $z$ & $\mathrm{p}$ & 4 & 3 & 4 & 3 & 4 & $\vdots$ & 3 & 4 & 4 & 4 & 3 & 2 & 2 & 2 & 3 & 4 & 4 & 56 \\
\hline 3 & AMI & $\mathrm{p}$ & 2 & 3 & 3 & 3 & 3 & 2 & 3 & 3 & 3 & 3 & 3 & 2 & 2 & 2 & 3 & 3 & 3 & 46 \\
\hline 4 & ARM & $\mathrm{p}$ & 4 & 4 & 4 & 4 & 3 & $\vdots$ & 4 & 4 & 4 & 4 & 4 & 3 & 3 & 2 & 4 & 4 & 4 & 62 \\
\hline 5 & $\mathrm{EH}$ & P & 4 & 4 & 4 & 4 & 3 & $\underline{\xi}$ & 4 & 4 & 4 & 4 & 4 & 3 & 3 & 3 & 4 & 4 & 4 & 63 \\
\hline 6 & DNG & $\mathrm{P}$ & 3 & 4 & 4 & 4 & 3 & $\vdots$ & 3 & 3 & 4 & 4 & 4 & 3 & 3 & 2 & 3 & 4 & 4 & 58 \\
\hline 7 & $\mathrm{FW}$ & $\bar{P}$ & 3 & 3 & 4 & 4 & 3 & $\vdots$ & 3 & 3 & 3 & 3 & 3 & 3 & 2 & 2 & 3 & 3 & 3 & 51 \\
\hline 8 & $\mathrm{VN}$ & $\mathrm{P}$ & 2 & 2 & 3 & 2 & 3 & 2 & 2 & 3 & 2 & 3 & 2 & 2 & 2 & 2 & 2 & 2 & 2 & 38 \\
\hline 9 & GPS & P & 3 & 3 & 3 & 2 & 3 & $\vdots$ & 3 & 3 & 2 & 3 & 3 & 2 & 2 & 2 & 2 & 2 & 3 & 44 \\
\hline 10 & RY & p & 4 & 4 & 3 & 3 & 3 & $\vdots$ & 3 & 3 & 4 & 3 & 3 & 2 & 2 & 2 & 4 & 3 & 4 & 53 \\
\hline 11 & SF & p & 4 & 7 & 4 & 4 & 4 & 4 & 4 & 4 & 4 & 4 & 3 & 3 & 3 & 3 & 4 & 4 & 4 & 64 \\
\hline 12 & II & $\mathrm{p}$ & 2 & 2 & 3 & 3 & 3 & 2 & 2 & 3 & 2 & 3 & 3 & 2 & 2 & 1 & 2 & 2 & 2 & 39 \\
\hline 13 & MI & $\mathrm{p}$ & 3 & 3 & 3 & 3 & 3 & 2 & 3 & 3 & 3 & 4 & 4 & 2 & 3 & 2 & 3 & 3 & 4 & 51 \\
\hline 14 & $\mathrm{PR}$ & $\mathrm{p}$ & 3 & 3 & 3 & 2 & 3 & 2 & 3 & 3 & 3 & 3 & 4 & 2 & 3 & 2 & 3 & 3 & 3 & 48 \\
\hline 15 & $\mathrm{NH}$ & p & 3 & 3 & 3 & 3 & 3 & $\vdots$ & 3 & 3 & 3 & 3 & 3 & 2 & 3 & 2 & 3 & 3 & 3 & 49 \\
\hline 16 & LFN & p & 3 & 3 & 3 & 3 & 3 & 2 & 3 & 3 & 3 & 3 & 3 & 2 & 2 & 2 & 3 & 3 & 3 & 47 \\
\hline 17 & RG & $\mathrm{p}$ & 3 & 3 & 4 & 3 & 3 & $\vdots$ & 3 & 3 & 4 & 3 & 3 & 2 & 2 & 2 & 4 & 3 & 4 & 52 \\
\hline 18 & MR & P & 2 & 3 & 3 & 3 & 3 & 2 & 2 & 3 & 3 & 3 & 3 & 2 & 2 & 2 & 2 & 2 & 2 & 42 \\
\hline 19 & $\mathrm{NW}$ & $\mathrm{p}$ & 4 & 3 & 4 & 4 & 4 & $\vdots$ & 4 & 4 & 4 & 4 & 3 & 3 & 3 & 3 & 4 & 4 & 4 & 62 \\
\hline 20 & $\mathrm{sW}$ & $\mathrm{P}$ & 3 & 3 & 3 & 3 & 2 & 2 & 2 & 3 & 2 & 3 & 3 & 2 & 2 & 2 & 2 & 3 & 3 & 43 \\
\hline 21 & $\mathrm{MM}$ & $\mathrm{p}$ & 2 & 3 & 3 & 2 & 3 & 2 & 2 & 3 & 2 & 3 & 3 & 2 & 2 & 2 & 3 & 2 & 2 & 41 \\
\hline 22 & RV & $\mathrm{p}$ & 4 & 3 & 3 & 3 & 3 & $\vdots$ & 4 & 4 & 4 & 4 & 3 & 4 & 4 & 3 & 3 & 3 & 3 & 58 \\
\hline & umlah & & 68 & 69 & 75 & 68 & 68 & 58 & 66 & 73 & 70 & 75 & 71 & 52 & 54 & 47 & 68 & 67 & 71 & 1120 \\
\hline
\end{tabular}


Tabel 1.3

\begin{tabular}{|c|c|c|c|c|c|c|c|c|c|c|c|c|c|c|c|c|c|c|c|c|}
\hline \multirow[b]{3}{*}{ No } & \multicolumn{20}{|c|}{$\begin{array}{l}\text { REKAFITULASI HASII OBSER VASI PENELIIAN" } \\
\text { BERDASARKAN JENIS KELAMIL(LAK-LAKI) }\end{array}$} \\
\hline & \multirow[b]{2}{*}{ Nama } & \multirow[b]{2}{*}{$J_{k}$} & \multicolumn{17}{|c|}{ SEor Butir } & \multirow[b]{2}{*}{ Jumlah } \\
\hline & & & 1 & 2 & 3 & 4 & 5 & 6 & 7 & 8 & 9 & 10 & 11 & 12 & 13 & 14 & 15 & 16 & 17 & \\
\hline 1 & $\hat{h A}$ & $\mathrm{~L}$ & 3 & 3 & 2 & 2 & 3 & 2 & 3 & 3 & 3 & 3 & 2 & 2 & 2 & 2 & 2 & 3 & 2 & 12 \\
\hline$?$ & AF & $T$ & 3 & 3 & 3 & 2 & 4 & 3 & 3 & 3 & 3 & & 3 & I & 2 & 2 & 3 & 3 & 1 & 18 \\
\hline 3 & $\mathrm{DN}$ & L & 3 & 3 & 3 & 3 & 3 & 2 & 3 & 3 & & 3 & 3 & 2 & 2 & 1 & 3 & 3 & 3 & 45 \\
\hline 4 & III & $\mathrm{I}$ & 3 & 3 & ; & 3 & 3 & 2 & 3 & $\hat{i}$ & 2 & 3 & 3 & $\hat{i}$ & 3 & 2 & 3 & $?$ & 2 & 16 \\
\hline 5 & HIA & $I$ & 4 & 4 & 3. & 3 & 4 & 4 & 4 & 4 & 4 & 4 & 3 & $\frac{1}{3}$ & 3 & 4 & 4 & 4 & 4 & 63 \\
\hline 6 & $\mathrm{KI}$ & L & 3 & 3 & 3 & 2 & 3 & 2 & 3 & 3 & 2 & 3 & 2 & 2 & 2 & 2 & 2 & 2 & 1 & 42 \\
\hline 7 & $M Z A$ & $\mathrm{~L}$ & 3 & 3 & $\hat{3}$ & 3 & 3 & 3 & 3 & $\hat{i}$ & 3 & 3 & 3 & 2 & 2 & 2 & 3 & 3 & 7 & 48 \\
\hline ह & ND & $I$ & 2 & 2 & 1 & 2 & 3 & 2 & 2 & 3 & 2 & 3 & 2 & 2 & 2 & 2 & 2 & 2 & $z$ & 37 \\
\hline y & SR & $L$ & 2 & 3 & 2 & 3 & 3 & 2 & 2 & 2 & 2 & 3 & 3 & 2 & 2 & 2 & 2 & 2 & 2 & 40 \\
\hline 10 & $2 W 1$ & I & 4 & 3 & 4 & 4 & 3 & 3 & 4 & 4 & 4 & 4 & 3 & 3 & 3 & 2 & 3 & 4 & 3 & 58 \\
\hline 11 & SA & $T$ & 3 & 3 & 1 & 3 & 3 & 2 & 2 & 1 & 2 & 3 & 3 & 2 & 2 & 2 & 3 & 3 & \pm & 1) \\
\hline \multicolumn{3}{|c|}{ ЛIMT AH } & 33 & 33 & 32 & 30 & 35 & 27 & 32 & 36 & 29 & 35 & 30 & 25 & 25 & 23 & 30 & 31 & 30 & 516 \\
\hline
\end{tabular}

Dalam Peraturan Menteri No.16

Tahun 2007 Tentang Standar Kualitas Akademik dan Kompetensi Guru, dijelaskan bahwa kompetensi profesional dapat dijabarkan menjadi beberapa indikator di antaranya adalah 1) menguasai materi, stuktur, konsep, dan pola pikir keilmuan yang mendukung mata pelajaran yang diampu, 2) Menguasai standar kompetensi dan kompetensi dasar mata pelajaran atau bidang yang diampu, 3) Mengembangkan materi pelajaran yang diampu secara kreatif yang telah dijabarkan dalam 17 indikator.

Artinya agar memiliki kompetensi profesional mahasiswa calon guru dituntut untuk menguasai materi dengan baik. Berdasarkan hasil penelitian yang telah dilakukan terkait kompetensi profesional calon guru PAI di IAIN Batusangkar, maka di dapatkan gambaran bahwa untuk persentase secara keseluruhan dari 17 item indikator yang diamati maka didapatkan persentasenya kompetensi profesional mahasiswa perempuan diperoleh sebesar 59,9 \% dengan kategori "cukup mampu". Sedangkan persentase untuk mahasiswa laki-laki didapatkan sebesar 55,2\% dengan kategori "cukup mampu".

Dari hasil penelitian yang diperoleh dapat dipahami bahwa ada beberapa kemampuan yang perlu ditingkatkan lagi oleh mahasiswa agar nantinya mampu menjadi guru yang memiliki kompetensi profesianal. Di antaranya adalah terkait penguasaan mahasiswa terhadap materi yang akan diajarkan. Mahasiswa memiliki kelemahan dalam menguasai materi, serta sulit untuk memberikan contoh-contoh lain yang lebih konkrit. Penulis melihat salah satu faktor yang mempengaruhinya adalah rendahnya minat baca dikalangan mahasiswa. Minat untuk membaca buku terkait keilmuan serta memperdalam ilmu dengan membaca berbagai referensi sudah mulai berkurang di kalangan mahasiswa. Hal ini dapat dilihat pada saat perkuliahan berlangsung. Mereka cenderung bersikap pasif dalam perkuliahan dengan alasan tidak mampu bersikap aktif disebabkan tidak memilki pengetahuan terkait topik yang sedang dibahas.

Sebagian besar mahasiswa lebih senang menerima apa yang disampaikan dosen di kelas dibandingkan mereka mencari tahu sendiri dengan membaca berbagai literatur yang ada serta membagi informasi tersebut kepada teman lainnya di kelas. Di samping itu, suasana akademisi sudah mulai memudar di kalangan mahasiswa. Idealnya mahasiswa 
menghabiskan waktu untuk melakukan diskusi ilmiah, membaca buku ilmiah serta memanfaatkan perpustakaan sebagai sarana untuk belajar.

Fenomena yang ditemukan di atas sejalan dengan hasil penelitian yang telah dilakukan oleh Deni Hardianto yang berjudul "Studi tentang Minat Baca Mahasiswa Fakultas Ilmu Pendidikan UNY” tahun 2011 dimana hasil penelitiannya menggambarkan beberapa hal pertama minat membaca mahasiswa FIP UNY secara umum termasuk dalam kategori rendah. Kedua aktivitas mahasiswa di kampus paling banyak adalah menunggu di depan kelas dan sedikit sekali mahasiswa yang memanfaatkan waktu luang untuk membaca buku atau berkunjung ke perpustakaan.

Ketiga buku teks ilmiah kurang diminati untuk dibaca karena beberapa hal di antaranya tulisannya terlalu kaku, bahasanya sulit dipahami, layout yang tidak menarik dan lain-lain. Keempat, intensitas waktu yang diluangkan mahasiswa dalam membaca relatif rendah, yaitu kurang dari 1 jam tiap harinya bahkan ada yang tidak perna sama sekali meluangkan waktu untuk membaca.kecuali saat-saat menjelang ujian. Kelima faktor yang menghambat mahasiswa dalam membaca, yang paling besar adalah berasal dari dalam diri mahasiswa yang ditunjukan dengan kebiasaan atau kegemaran membaca yang sangat rendah.( Hardianto, 2011:108)

Adapun faktor yang menyebabkan mahasiswa malas dalam membaca di antaranya disebabkan oleh faktor internal dalam diri mereka sendiri. Minat, serta rasa ingin tahu yang rendah menyebabkan mereka hanya berbekal apa adanya saja dalam menyampaikan materi. Hal ini juga didukung oleh hasil penelitian Sasmi Farida yang berjudul Faktor-Faktor Penyebab Keengganan Membaca Di Lingkungan Mahasiswa yang mengungkapkan bahwa mahasiswa enggan membaca disebabkan karena beberapa hal yaitu 1), tugas-tugas kuliah tidak banyak menuntut mahasiswa untuk membaca, 2) perpustakaan tidak memadai, 3) membaca belum menjadi sebuah budaya dikalangan mahasiswa, 3) mahasiswa sibuk dengan kegiatan, 4) adanya perasaan malu diolok-olok teman. Adapun faktor yang paling dominan yang membuat mahasiswa malas membaca adalah faktor internal yaitu berasal dari diri mereka sendiri. Hasil penelitian ini membuktikan bahwa tidak seorang pun dari responden yang mempunyai kebiasaan membaca. (Farida, 2012: 321).

Di samping faktor di atas penulis juga melihat faktor kecemasan pada saat tampil di depan umum juga memberikan pengaruh bagi mahasiswa ketika menyampaikan materi. Faktor kecemasan ini juga merupakan efek dari kurangnya persiapan yang dimiliki mahasiswa. Baik persiapan secara fisik, mental maupun penguasaan terhadap materi yang akan disampaikan itu sendiri. Kecemasan yang terjadi pada mahasiswa bisa disebabkan oleh beberapa faktor. Hal ini juga di dukung oleh hasil penelitian yang dilakukan oleh Hidayatullah, dan Martunis Yahya yang berjudul Analisis Faktor-Faktor Dalam Mempengaruhi Kecemasan Berkomunikasi di dapan Publik (Studi Mahasiswa FISIP dan FKIP Universitas Syiah Kuala) penelitiannya menjelaskan bahwa penyebab kecemasan mahasiswa FISIP dan FKIP Universitas Syiah Kuala adalah kurangnya persiapan dan pengalaman, faktor lingkungan sampai faktor audiens yang hadir ( Hidayatullah, 2017:1)

Di samping penguasaan materi bagi mahasiswa perlu ditingkatkan yaitu dengan cara banyak membaca, aspek lain yang juga perlu ditingkatkan adalah pemanfaatan teknologi informasi secara lebih kreatif lagi yang nantinya sangat dibutuhkan dalam merancang sebuah media pembelajaran.Dari penelitian yang telah dilakukan di dapatkan gambaran bahwa mahasiswa memilki kelemahan dalam menyajikan materi secara kreatif seperti menggunakan mind map ataupun update informasi terkait keilmuan yang mereka miliki.Meskipun mahasiswa sekarang hidup di zaman yang serba canggih 
dengan perkembangan teknologi informasi yang begitu pesat tidak menjamin bahwa mahasiswa mampu memanfaatkannya sebagai sarana pendukung yang dapat digunakan sebagai sumber belajar serta dapat membuat mereka lebih kreatif lagi.

Mahasiswa bukan tidak mampu memakai teknologi, akan tetapi teknologi tersebut pemanfataannya perlu dilakukan lebih bijak dan untuk hal-hal yang bermanfaat. Sejalan dengan uraian di atas penelitian yang telah dilakukan oleh Arif Budhi Utama yang berjudul Pemanfaatan Teknologi Informasi di Kalangan Mahasiswa Universitas Negeri Surabaya. Hasil penelitiannya menjelaskan bahwa pemanfaatan TIK secara aktif di kalangan Mahasiswa Universitas Negeri Surabaya sangat signifikan. Kebanyakan dari mahasiswa Universitas Negeri Surabaya aktif berjejaring sosial dan kebanyakan dari mereka mempunyai lebih dari 1 akun jejaring sosial. Situs jejaring sosial yang paling digemari oleh mahasiswa Universitas Negeri Surabaya adalah facebook. Namun pemanfaatan TIK secara kreatif dan inovatif masih sangat kurang. Ini terbukti dengan rendahnya kepemilikan website atau weblog.

Ada beberapa responden yang mengaku mempunyai website atau weblog namun hanya sebagian kecil dari mereka yang secara rutin memposting artikel ke dalam website atau weblog yang mereka miliki. Dalam berjejaring sosialpun juga demikian. Kebanyakan mahsiswa Universitas Negeri Surabaya lebih tertarik pada status teman jejaring sosial mereka daripada berita - berita yang bersifat informatif. Perkembangan teknologi ini mempunyai dampak yang sangat besar bagi mahasiswa baik secara positif maupun negatif. Dengan memanfaatkan teknologi yang ada mahasiswa bisa belajar dan mengakses berbagai informasi mutakhir yang dibutuhkan untuk menambah wawasan. Berkaitan dengan hal ini, tentu perkembangan teknologi memberikan dampak yang positif bagi mahasiswa.
Di samping itu, perkembangan teknologi informasi dapat mengakibatkan berkurangnya kreatifitas dan berfikir kritis dikalangan mahasiswa. Tidak sedikit mahasiswa yang malas untuk pergi ke perpustakaan untuk mencari referensi, akan tetapi mereka lebih memilih untuk searching di google dan melakukan copy paste. Hal ini tentu memberikan pengaruh yang negatif bagi mahasiswa, mereka tidak mau lagi mengeksplor kemampuan yang mereka miliki. Dampaknya, budaya kreatifitas, kritis, dan aktif dikalangan mahasiswa sudah mulai menurun.

Sejalan dengan yang dikemukakan di atas Riska Fajar Arista, dan Refti Handini Lestyani melakukan penelitian yang berjudul "Plagiarisme di Kalangan Mahasiswa”. Penelitiannya menggungkapkan bahwa motif mahasiswa melakukan plagiat terdiri dari beberapa macam alasan, dari tiap angkatan yang menjadi informan menjelaskan bahwa mereka pernah melakukan plagiat secara sadar dan tidak sadar.

Dari penelitian ini beberapa informan yang diambil menjelaskan bahwa mereka melakukan plagiat karena alasan, pertama plagiat dilakukan karena budaya dosen mengajar. Budaya disini berkaitan dengan kebiasaan dan cara mengajar dosen yang tidak terarah dan tidak sesuai tema sehingga menyulitkan siswa untuk memahai, keduan plagiat dilakukan karena akses informasi yang mudah diperoleh dari mana pun, handphone yang canggih dan memudahkan untuk mencari sumber referensi yang bergram dari internet kemudahan tersebut disalahgunakan dengan langsung mengambil karya orang lain dalam mengerjakan tugas kuliah. Ketiga karena mengingingkan nilai yang baik diakhir semester. Nilai sebagai acuan untuk melakukan plagiat. Orientasi nilai yang dikejar mahasiswa melupkan proses yang baik sehingga segala sesuatu yang berkaitan dengan tugas, ujian dikerjakan dengan segala cara yang penting selesai. Keempat motif melakukan plagiat karena 
rendahnya pengawasan dan sanksi kepada mahasiswa yang melakukan plagiat ketika mengerjakan ujian dan mengerjakan tugas.

Bentuk-bentuk plagiat yang dilakukan mahasiswa beragram.Plagiat ini dibagi menjadi dua yakni plagiat ketikan mengerjakan soal ujian dan plagiat ketika mereka mengerajakan tugas kuliah.Plagiat mengerjakan soal ujian ini adalah dalam bentuk menyintek inti, ide maupun keseluruhan isi jawaban soal kepada teman. Kemudian bentuk plagiat dalam mengerjakan tugas ini adalah melakukan plagiat secara keseluruhan terhadap karya orang lain dan mengakui sebagai karya sendiri ataupun mengutip karya orang lainn dan tidak mencantumkan sumber asli.

\section{DAFTAR KEPUSTAKAAN}

Anwar, Khaidir. 1995. Beberapa Aspek Sosio-kultural Masalah Bahasa, Yogyakarta: Gadjah Mada University Press.

Chambert, Hendri-Loir. 1950. Naik haji di Masa Silam tahun 1900-1950. Jakarta: Gramedia.

Daniel, Mardiyiah. 1986. Wanita Minangkabau di Tengah Adat dan Agama (Studi Kasus Peranan Wanita dalam Pembangunan di Kecamatan Banuhampu di Daerah Minangkabau). Jakarta: IAIN Jakarta (Tesis).

Daya, Burhanuddin. 1995. Gerakan Pembaruan Pemikiran Islam Kasus Sumatera Thawalib. Yogyakarta: Tiara Wacana.

Hamka, Tenggelamnya Kapal Van Der Wijck, (Jakarta: Bulan Bintang, 1984).

Helfi, Kritik Abdul Karim Amrullah terhadap Budaya Lokal Minangkabau dalam Tafsir alBurhan, (Surabaya: UIN Sunan Ampel Surabaya, 2018).

\section{KESIMPULAN DAN REKOMENDASI}

Berdasarkan hasil penelitian yang telah dilakukan terkait kompetensi profesional calon guru PAI di IAIN Batusangkar maka di dapatkan gambaran bahwa kompetensi profesional calon guru PAI masuk dalam kategori "cukup". Meskipun dalam kategori yang sama namun ada perbedaan persentase yang diperoleh oleh mahasiswa berjenis kelamin perempuan dengan mahasiswa berjenis kelamin lakilaki. Persentase untuk mahasiswa perempuan lebih tinggi dibandingkan mahasiswa laki-laki.

Kemal, Iskandar, Beberapa Studi tentang Minangkabau, (Padang: Universitas Andalas, 1971).

Lubis, Junaidi, Islam Dinamis: Model ijtihad al-Khulafa al-Rasyidun dan Konteks Perubahan Masyarakat, (Jakarta: Dian Rakyat, 2010).

Noer, Deliar. 1990. Muhammad Hatta Biografi Politik. Jakarta: LP3ES.

Pangulu, Idrus Hakimi Datuak Rajo. 1980. Pegangan Penghulu dan Bundo Kanduang di Minangkabau. Bandung.

Rahardjo, M. Dawam. 1987. Pergumulan Dunia Pesantren Membangun dari Bawah. Jakarta: LP3ES.

Saydam, Gauzali. 2004. Kamus Lengkap Bahasa Minang. Padang: Pengkajian Bahasa Minang.

Schrieke, B.J.O. 1973. Pergolakan Agama di Sumatera Barat Sebuah Sumbangan Bibliografi, Terj, Soegarda Poerbakawatja. Jakarta: Bharatara.

Yunus, Mahmud. 1979. Sejarah Pendidikan Islam. Jakarta: Mutiara. 